\title{
Los medios impugnatorios en el proceso penal
}

Marco Antonio Ulloa Reyna

Abogado. Docente de la Universidad Alas Peruanas. Estudios de maestría y de doctorado. Postgrado en Administración de Justicia por la Universidad Nacional Mayor de San Marcos. Ex Magistrado de la Corte Superior de Justicia de Lima.
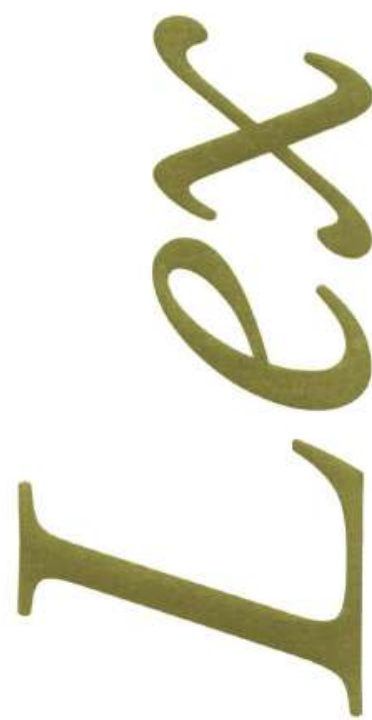


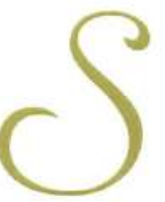

e denominan medios impugnatorios a aquellos mecanismos procesales establecidos por la ley, con respaldo constitucional y supranacional, que posibilitan a los sujetos procesales legitimados solicitar a un magistrado (al mismo juez o al superior en grado) que reexamine un acto procesal o todo un proceso que le ha causado perjuicio, a fin de lograr que el hecho materia de cuestionamiento sea revocado, modificado o anulado, ya sea parcial o totalmente.

Esta definición implica un reexamen del acto procesal o de todo un proceso, siendo que, para acogerse a dicho mecanismo, el sujeto procesal debe estar debidamente legitimado en el proceso (Ministerio Público, imputado, actor civil o tercero civilmente responsable).

La revisión del acto procesal impugnado está a cargo del propio magistrado que emitió la resolución (cuando se trate del recurso de reposición), o a cargo de otro magistrado superior en grado (cuando se trata de otro tipo de medio impugnatorio).

Los efectos del recurso o medio impugnatorio son la anulación o revocación del acto procesal.

\section{Jurisprudencia relacionada con la legitimidad de los actores procesales}

1. Tratándose de sentencias condenatorias, necesariamente se deberá notificar a la parte civil para el acto de la emisión final. Habiéndose ello omitido, se ha atentado contra el derecho de defensa, declarándose nula la sentencia.

EXP. No 640-98 (4c)

Lima, cinco de junio de mil novecientos noventa y ocho.

Vista: Interviniendo como Vocal ponente la doctora Victoria Sánchez Espinoza; de conformidad con lo opinado por el señor Fiscal Superior, y ATENDIENDO: A que es garantía de la 
administración de justicia, el «no ser privado del derecho de defensa en ningún estado del proceso"; que siendo así y de conformidad con lo señalado en el artículo cincuenta y ocho del Código de Procedimientos Penales, el agraviado debidamente constituido en parte civil será notificado de todas las resoluciones que recaigan dentro del proceso a fin de poder ejercer los recursos impugnatorios pertinentes y tratándose de sentencias condenatorias necesariamente se deberá notificar a esta parte para el acto de emisión de la resolución final, conforme lo establece el artículo sexto del Decreto Legislativo ciento veinticuatro; que en el caso de autos se ha omitido cumplir con dichas disposiciones al no citar al Procurador Público, quien vela por los intereses del Estado, al no obrar en el expediente de los cargos de notificación respectivos que demuestren lo contrario habiendo de esta forma atentando contra el derecho invocado; normas que por su carácter procesal son de orden público y de estricto cumplimiento que de otro lado, conforme lo expresa el abogado del acusado Jorge Alberto Cueva Portilla en su escrito, de fojas doscientos treinta y dos, también se ha omitido notificar a su patrocinado con arreglo a ley para el acto procesal en cuestión, pues conforme es de verse a fojas doscientos veintiuno, erróneamente se le ha cursado citación al domicilio de su anterior abogado; sin tener en cuenta que por escrito obrante a fojas trescientos treinta y dos del expediente acumulado, nombró al doctor Abelardo Vivas Payano como su nuevo abogado defensor, variando su domicilio legal, lugar donde anteriormente ya se le venía notificando como es de verse de fojas ciento ochenta y uno y doscientos diecinueve, habiendo incluso participado este letrado en su declaración instructiva; por lo que no siendo subsanables las omisiones a la norma procesal anotadas, de conformidad con el artículo doscientos noventa y ocho del Código de Procedimientos Penales, DECLARARON: NULA la sentencia apelada de fojas doscientos veintiséis y siguientes, su fecha diecisiete de diciembre de mil novecientos noventa y siete en el extremo que declara FUNDADA la excepción de naturaleza de acción deducida por el acusado Zenón Ignacio Marcos Cueva en la instrucción que se le sigue por delito contra el Patrimonio Estafa en agravio de Maura Juárez Valdiviezo de Farfán; ABSUELVE de la acusación Fiscal a ZENÓN IGNACIO MARCOS CUEVA por delito contra la Fe Pública - Falsificación de Documentos y CONDENA a ZENÓN IGNACIO MARCOS CUEVA por delito contra el Patrimonio - Defraudación y contra la Administración de Justicia en agravio de Maura Juárez Valdiviezo de Farfán y el Estado a DOS AÑOS DE PENA PRIVATIVA DE LA LIBERTAD, cuya ejecución se suspende condicionalmente por el plazo de un año, bajo reglas de conducta y fija: en la suma de tres mil nuevos soles el monto que por concepto de Reparación Civil deberá abonar el sentenciado a favor de los agraviados; con lo demás que contiene; DISPUSIERON: Que los autos pasen a otro Juez, quien previa a la expedición de nueva sentencia deberá subsanar las omisiones anotadas, LLAMARON: por esta única vez severamente la atención a la Juez de la causa recomendándosele que ponga mayor celo en el desempeño de sus funciones; notificándose y los devolvieron. 


\section{SS. ESTRADA CHOQUE / SÁNCHEZ ESPINOZA / PORTUGAL HIDALGO}

\section{Parte civil: Resolución de Admisión (robo agravado)}

Para que la parte agraviada pueda interponer los recursos impugnatorios que prevé el artículo 58 del Código de Procedimientos Penales, requiere de resolución que le tenga expresamente constituida como parte civil; no bastando el apersonamiento o el pedido de dicha parte.

Expediente 3608-95-B

SALA PENAL

CAJAMARCA

Lima, tres de septiembre de mil novecientos noventa y seis.

VISTOS; y CONSIDERANDO: que las normas procesales son de orden público y, consecuentemente, de obligatorio cumplimiento; que la parte agraviada, a efectos de interponer los recursos impugnatorios que prevé el artículo cincuenta y ocho del Código de Procedimientos Penales, requiere de resolución que la tenga expresamente constituida como parte civil; que, en consecuencia, no basta el apersonamiento o el pedido de dicha parte, sino de resolución expresa que la admita como tal, tanto más si dicho pronunciamiento puede ser objeto de oposición por el Ministerio Público y el propio inculpado; que, por tanto, no apareciendo de autos que a Venancia Aranda Armas se le tenga expresamente como parte civil, no obstante haberlo solicitado tanto a fojas setenta y ocho como a fojas ciento sesenta y cuatro y no haber sido proveído en su debida oportunidad, el Juez Penal y los señores vocales intervinientes son pasibles de la medida disciplinaria a que se refiere el artículo doscientos nueve de la Ley Orgánica del Poder Judicial; declararon INSUBSISTENTE el concesorio del recurso de nulidad de fojas ciento noventa, su fecha doce de julio de mil novecientos noventa y cinco; e IMPROCEDENTE la solicitud de su propósito de fojas ciento ochenta y nueve; en la instrucción seguida contra José Maximiliano Aranda Escobedo y otro, por el delito contra el patrimonio -robo agravado- en agravio de Venancia Aranda Armas; IMPUSIERON la medida disciplinaria de MULTA del dos por ciento de su haber mensual al Juez Penal doctor Milliam Héctor Moreno Zavaleta y a los Vocales Superiores doctores Nelson Silva Chávez, Tomás Padilla Martos y Mazarino Bazán Zegarra, conforme a lo previsto por el artículo doscientos nueve de la Ley Orgánica del Poder Judicial; y los devolvieron.

\footnotetext{
S.S. MONTES DE OCA BEGAZO / BECERRA BARRANTES / SAPONARA MILLIGAN / BERNAL MATALLANA / FERNÁNDEZ URDAY
} 
3. Agraviados que habiendo interpuesto recurso impugnatorio ante la Corte Suprema, sin haberse constituido previamente en parte civil carecen de personería para interponer los recursos a que se refiere el artículo 58 del Código de Procedimientos Penales.

Expediente 3763-95-B

SALA PENAL

PUNO

Lima, diez de septiembre de mil novecientos noventa y seis.

VISTOS; y CONSIDERANDO: que, conforme se tiene del auto de apertura de instrucción de fojas cuarenta, ampliado a fojas ochenta y seis, ciento cincuenta, ciento setenta y cinco y ciento noventa y cuatro, se ha instruido proceso penal contra Oswaldo Guadulfo Díaz Durante y Emilio Raúl Zaga Catacora, por el delito de violencia y resistencia a la autoridad, habiéndose consignado como agraviados a Juan Segundo Pérez Huanca, Juan Huisa Quispe y Pío Huisa Quispe, los cuales no se han constituido en autos como parte civil, empero se ha elevado el presente proceso a esta Suprema Instancia en virtud del recurso impugnativo interpuesto por los agraviados; que, estando a lo glosado, no teniendo los agraviados la personería que confiere el artículo cincuenta y ocho del Código de Procedimientos Penales para interponer los recursos a que se refiere dicho numeral: declararon INSUBSISTENTE el concesorio de fojas doscientos catorce vuelta, su fecha quince de agosto de mil novecientos noventa y cinco, e IMPROCEDENTE el recurso de nulidad de su propósito de fojas doscientos trece; en la instrucción seguida contra Oswaldo Guadulfo Díaz Durante y otro, por el delito de violencia y resistencia a la autoridad en agravio de Juan Segundo Pérez Huanca y otros; y los devolvieron.

\section{S.S. MONTES DE OCA BEGAZO / BECERRA BARRANTES / SAPONARA MILLIGAN / BERNAL MATALLANA / FERNÁNDEZ URDAY.}

\section{NATURALEZA JURÍDICA DE LOS MEDIOS IMPUGNATORIOS}

Derecho de impugnación - Derecho de Acción

Impugnación: Derecho abstracto (ejercicio no requiere existencia real de afectación).

Impugnación continuación del ejercicio del derecho de acción (Derecho continente).

El maestro Binder en su libro Introducción al Derecho Procesal Penal señala que se puede analizar los medios de impugnación desde dos perspectivas fundamentales: una como un derecho de impugnación ligado al valor "seguridad jurídica» y como un medio para evitar errores judiciales en el caso concreto; la otra perspectiva se basa en la necesidad social de que las decisiones judiciales sean correctas (o cumplan su función pacificadora ), y el Derecho sea aplicado de un modo uniforme y equitativo . 
-Derecho de impugnación tutela jurisdiccional efectiva

-Tutela jurisdiccional efectiva antes del proceso.

-Asegurar el ejercicio del derecho de acción

(órganos, funcionarios y normas).

-Tutela jurisdiccional efectiva dentro del proceso.

-Asegurar el ejercicio del derecho de defensa

(contradicción, probanza e impugnación).

-Impugnación - Debido proceso

- Debido proceso adjetivo:

Conjunto de elementos (o reglas) de observancia obligatoria en la tramitación de un proceso justicia.

Medios impugnatorios y control jurisdiccional

Medios impugnatorios - Interés de sujetos procesales en controlar decisiones judiciales.

A los sujetos procesales les interesa que la decisión judicial sea controlada, ya que constituye una garantía de orden constitucional, supranacional y legal.

- Control jerárquico interno y externo

El Poder Judicial es un Poder del Estado debidamente jerarquizado en distintos niveles de composición que permite establecer un autocontrol y también existen mecanismos externos que permiten otro tipo de control de parte del magistrado constitucional; asimismo, el Estado tiene interés en controlar la aplicación del Derecho por parte de los jueces.

- Control - Unificación de criterios

Se realiza por intermedio del más alto tribunal de Justicia de la Republica.

- Control - Carácter dispositivo

Implica que las partes son las que ejercen el control, siendo la labor del magistrado que va a resolver el medio impugnatorio pronunciarse en base a las alegaciones efectuadas por las partes.

\section{Impugnación y reconocimiento normativo}

Nuestra Carta Magna reconoce la instancia plural como una derivación del derecho que le asiste a todo justiciable a poder impugnar una resolución judicial. 
Igualmente, la Ley Orgánica del Poder Judicial en su artículo 11 establece que las resoluciones judiciales son materia de revisión por el órgano superior.

Las partes pueden hacer valer su derecho, constituyendo por tanto el cumplimiento de los principios dispositivo y el de legalidad, aunado al principio de doble instancia, que no solo tiene carácter constitucional sino que es recogido por el artículo X del Título Preliminar del Código Procesal Civil y el artículo I del Titulo Preliminar y artículo 404 del Nuevo Código Procesal Penal.

A su vez, por el artículo 14.5 del Pacto Internacional de Derechos Civiles y Políticos y artículo 8.2 de la Convención Americana sobre Derechos Humanos.

\section{Clasificación}

- De acuerdo al Código Procesal Civil

Recursos: reposición, apelación, casación y queja.

- De acuerdo al Código Procesal Penal

No existe propiamente una clasificación.

Recursos: reposición, apelación, casación y queja. Artículo 413 del Nuevo Código Procesal Penal.

Remedios: Nulidades (artículo 149 y siguientes del Nuevo Código Procesal Penal).

Revisión (artículo 439 y siguientes del Nuevo Código Procesal Penal).

- Por la atribución del Órgano Revisor

Propios positivos: revocación.

Propios negativos: anulación.

Y dentro de este último, con indicación expresa al inferior y a consideración del inferior.

Casación: positivo o negativo.

- Por el Órgano Revisor

Propios: revisión por el órgano superior (apelación; artículo 417 del Nuevo Código Procesal Penal).

Impropios: revisión por el mismo órgano (reposición; artículo 415 del Nuevo Código Procesal Penal).

- Por la trascendencia del acto procesal impugnado

Principales: contra las resoluciones que ponen fin al proceso.

Incidentales: contra resoluciones interlocutorias. 
- Por las formalidades exigidas

Ordinarios (requisitos normales; apelación).

Extraordinarios (requisitos específicos; casación).

\section{Principios}

1. Principio de legalidad. Los recursos solo pueden interponerse cuando estén expresamente previstos en la ley.

2. Principio de formalidad. Ejercicio de acuerdo al procedimiento. Requisitos de procedencia y admisibilidad. Este principio posibilita que solo se puede hacer uso de los recursos conforme a lo establecido por la normatividad vigente para cada uno de los medios impugnatorios señalados por la ley.

3. Principio de consumación. Elección errónea no subsanable.

4. Principio dispositivo. Los recursos solo pueden ser interpuestos por los sujetos procesales legitimados.

La norma establece quiénes son los sujetos legitimados que pueden recurrir a los medios impugnatorios. La persona que carece de legitimidad no puede presentarse al proceso, siendo la excepción los recursos de oficio o la consulta que procede en los casos previstos por la ley.

Congruencia procesal. El pronunciamiento del revisor debe ser solo respecto a la materia de impugnación. Cuando una causa va a ser materia de un reexamen, ya sea de parte del propio magistrado que dictó la resolución en el caso de un decreto, por ejemplo, o cuando sea examinada por el superior en grado, lo hace sobre la materia impugnada. No cabe que el revisor se pronuncie sobre algo que no ha solicitado la parte afectada ni tampoco emita un pronunciamiento más allá de lo solicitado ni resuelva concediendo cosa distinta (Extra petita).

5. Principio de unicidad. Un solo recurso para impugnar determinado tipo de resolución. No cabe hacer uso de varios medios impugnatorios ni tampoco en forma subsidiaria.

6. Principio de trascendencia. Solo puede presentar el medio impugnatorio el sujeto debidamente legitimado que haya sufrido el agravio; este principio debe ser materia de examen tanto por el magistrado que concede el recurso impugnatorio como por el magistrado revisor, teniendo en cuenta que su inobservancia produce la nulidad del acto procesal que concede el recurso. 
*Adhesión. Artículo 404, inciso 4 del Nuevo Código Procesal Penal.

Mediante este recurso se posibilita que el sujeto procesal con derecho a impugnar que no lo haya hecho, lo pueda hacer al adherirse al recurso interpuesto por cualquier otro sujeto procesal, para lo cual deberá hacerlo antes que los autos sean elevados al superior. Para ello deberá tener en cuenta las formalidades señaladas en la ley.

*Desistimiento. Este recurso establece la autonomía que tienen las partes para, si lo creen conveniente, retirar su escrito de impugnación, y lo pueden hacer hasta antes de que se expida la resolución de revisión.

Los efectos del desistimiento son personales y no atañen a otros sujetos procesales que hayan impugnado el mismo acto procesal, ni tampoco a los que se han adherido posteriormente.

El sujeto procesal que se desista deberá indicar los motivos por los cuales ha tomado la decisión de dejar sin efecto su recurso impugnatorio.

7. Principio de instancia plural. Los medios impugnatorios implican un reexamen integral por otra instancia superior, lo que trae consigno una seguridad jurídica y control del magistrado que dictó la resolución impugnada y pueda haber cometido un error.

8. Principio de inmediación. El órgano de revisión debe formar su convicción sobre el material probatorio actuado en su presencia y no en base a las actuaciones efectuadas en la instancia que dictó el acto procesal objeto de la impugnación.

\section{Prohibición de REFORMATIO IN PEIUS}

Es la prohibición al órgano revisor de no empeorar la situación del impugnante.

El Tribunal Constitucional ha establecido en sus sentencias que los medios impugnatorios forman parte del debido proceso, y están relacionadas con el derecho de defensa, por lo que los fallos del revisor no pueden agravar la condición del impugnante.

Presupuestos

a) Presupuestos subjetivos

Sujetos procesales (dispositivo)

Agravio (trascendencia)

b) Presupuestos objetivos

Formalidades 
Por escrito (la forma oral solo contra resoluciones finales expedidas en audiencias).

Plazos (contados desde el día siguiente a la notificación).

Reposición: 2 días.

Apelación: 5 días (sentencias) y 3 días (autos).

Casación: 10 días.

Queja: 3 días.

Fundamentación

En qué consisten los agravios:

-Fundamentos de hecho y de derecho.

-Precisión de pretensión impugnada.

Control de la admisibilidad

Primero: ante el juez ante quien se interpone.

Segundo: órgano revisor.

\section{Efectos jurídicos}

-El reexamen de la resolución impugnada está a cargo del superior en grado.

-Cesa la competencia del a quo.

-Adquem asume competencia revisora.

-Reposición no efecto devolutivo.

-Efecto extensivo

Los efectos de la interposición de un recurso por un sujeto procesal se extienden a los demás en cuanto se encuentra en la misma situación y los favorezca.

-Efecto diferido

Procesos con pluralidad de imputados o delitos.

Supuesto: se dicta auto de archivo a favor de uno de los procesados, pero está pendiente el juzgamiento de otros; se concede el medio impugnatorio, pero se reserva la elevación hasta que se dicte sentencia.

-Efecto suspensivo

Imposibilidad de ejecutar la resolución impugnada.

La apelación tiene efecto suspensivo (sentencias, autos de sobreseimiento, autos que pongan fin a la instancia).

-Efecto devolutivo

Revisión a cargo del órgano superior.

-Materia de impugnación con capacidad de anulación

Se puede revisar la aplicación del derecho o la declaración de hechos.

Se puede anular o revocar total o parcialmente (condenar a un absuelto).

Se requiere para la formación de resolución únicamente de dos votos conformes. 


\section{Actos impugnables.}

1. Recurso de reposición. Procede solo contra los decretos (simple trámite), siendo el propio órgano revisor el mismo juez. Se basa en el principio de economía procesal.

2. Recurso de apelación. Procede contra autos y sentencias, y existe doble control de la admisibilidad del recurso, primero por el propio juez y luego por el magistrado revisor. En relación a la apelación de autos, el trámite es distinto al de las sentencias, ya que para los autos se corre traslado a las partes por cinco días, luego se procede a la admisibilidad del recurso y audiencia, teniendo veinte días para resolver el grado; mientras que en las sentencias se corre traslado cinco días para los agravios. La calificación de admisibilidad se comunica a las partes, que pueden ofrecer medios probatorios que son materia de calificación por el órgano revisor. Luego de los alegatos e informes orales se da por concluido el debate y el órgano revisor decide en el plazo de diez días.

3. Recurso de casación. Procede solo contra determinadas resoluciones y motivos tasados. Exigencia de mayores formalidades, sentencias definitivas, extremo mínimo seis años para el delito más grave, autos que pongan fin al procedimiento, autos que denieguen extinción, conmutación, reserva o suspensión de la pena, pretensión indemnizatoria de 50 URP. La Corte Suprema al actuar como Corte Casatoria no constituye instancia. Las causales son la inobservancia, aplicación indebida o interpretación errónea de garantías constitucionales de carácter procesal o constitucional, inobservancia de una norma procesal (nulidad), aplicación indebida, interpretación errónea o inaplicación de la ley penal o de otra norma necesaria para su aplicación. El plazo de presentación es de diez días, por escrito debidamente fundamentado, en el que se fijará la causal o sustento y cuál es la pretensión impugnatoria, la no conformidad con la sentencia de primera instancia confirmada en segunda, denuncia de infracciones y el hecho de que la recurrida se ha apartado de la doctrina jurisprudencial; luego viene la tramitación del recurso, pasando por una calificación a cargo del Colegiado Superior. La Sala Casatoria corre traslado para absolverlo, y posteriormente pasa por una segunda calificación dentro de un plazo de 20 días, en la que se declara procedente la admisibilidad. Luego se presentan los alegatos y la audiencia de casación. De no concurrir el recurrente, se declara inadmisible el recurso; finalmente, se pronuncia la Sala Casatoria.

4. Recurso de queja. Tiene por objeto la admisibilidad de otro recurso previamente denegado. El órgano de revisión se va a pronunciar sobre la resolución denegatoria, siendo su efecto devolutivo; el trámite se interpone ante el órgano revisor, y el escrito deberá precisar la norma vulnerada, adjuntándose el escrito que motivó la resolución recurrida, actuados referidos a su tramitación, resolución recurrida, escrito en el que se recurre y resolución de inadmisibilidad. 


\section{Conclusiones}

Con el Nuevo Código Procesal, nuestro sistema procesal identifica cada uno de los medios impugnatorios que la ley señala, cuál es el trámite que le corresponde, la legitimidad que debe tener el presentante del recurso, la doble calificación que debe tener el recurso tanto por el magistrado que expide la resolución impugnada como por el revisor.

Los medios impugnatorios tienen un sustento de orden constitucional y supranacional, identificándose en nuestro sistema procesal tanto en el Título Preliminar del Código Procesal Civil como en el Nuevo Código Procesal Penal, por lo que la preocupación de parte del Estado de crear mecanismos normativos de control internos y externos para los magistrados es de vital importancia por los errores en que pueden incurrir. En tal sentido, la doble garantía siempre implica una seguridad jurídica. Los medios impugnatorios son parte del debido proceso, al igual que la contradicción y la valoración de los medios probatorios. 


\section{Bibliografía}

- Julio B. Maier. Los recursos en el procedimiento penal. Editores del Puerto S.R.L., 2006.

- Ramón Teodoro Ríos. «Influencia de los principios acusatorios y de legalidad en la impugnación penal». Revista de Derecho Procesal Penal. Rubinzal - Culzoni Editores.

- Alberto M. Binder. Introducción al Derecho Procesal Penal. pp. 285 y ss. 